\title{
Pollen Morphology of Herbaceous Peonies with Different Ploidy Levels
}

\author{
Lihong Hao and Hui Ma \\ College of Landscape Architecture, Beijing Forestry University, Beijing, 100083, P.R. China
}

Jaime A. Teixeira da Silva

P.O. Box 7, Miki-cho post office, Ikenobe 3011-2, Kagawa-ken, 761-0799, Japan

\author{
XiaoNan $\mathbf{Y u}^{1}$ \\ College of Landscape Architecture, Beijing Forestry University, Beijing, 100083, P.R. China; and \\ Beijing Key Laboratory of Ornamental Plants Germplasm Innovation and Molecular Breeding, \\ National Engineering Research Center for Floriculture, Beijing, 100083, P.R. China
}

\begin{abstract}
Additional Index words. Paeonia
Abstract. The pollen morphology of 26 cultivars of herbaceous peony (Paeonia L.) was examined by scanning electron microscopy (SEM). Pollen grains of the cultivars were mostly subprolate to perprolate, tricolporate, or ellipsoidal in equatorial view, but rounded-trifid in polar view. The poles of pollen grains were mainly flat when viewed in cross-section and only a few appeared to have a circular or arc shape. In addition, the surface of the pollen grains was psilate, and the muri were partly or fully protuberant with a reticulate surface sculpture. However, the shapes and sizes of pollen grains as well as surface ornamentation varied significantly among cultivars with different chromosome numbers. The pollen grains from diploid cultivars were regular and full, and the reticulation holes were evenly distributed, while most of the pollen grains from triploid cultivars were empty flat shells with some heteromorphic pollen whose surface ornamentation was mostly rugulate-reticulate exine. The pollen grains from tetraploid cultivars were the largest although pollen morphology and surface ornamentation differed between Athena and Cream Delight. Six indices [polar axis length (P), equator axis length (E), P/E, pollen perforation diameter (D), ridge width $(\mathrm{W})$, and $\mathrm{D} / \mathrm{W}]$ were used in $\mathrm{Q}$ cluster analysis, which divided the 26 cultivars into three groups. Group $\mathrm{I}$ included eight diploid, four triploid, and one tetraploid cultivar. Group II included 12 triploid cultivars with complex genetic backgrounds. Group III included only one tetraploid cultivar Cream Delight. This work may provide an important palynological basis for studying taxonomy and hybrid breeding of herbaceous peony cultivars.
\end{abstract}

Herbaceous peonies, famous ornamental plants of the genus Paeonia (Paeoniaceae), have more than 1000 years of cultivation history around the world. Herbaceous peonies are usually divided into three distinct groups based on their provenance around the world, the Chinese Peony Cultivar Group [Lactiflora Group (LG)], the European Peony Cultivar Group [Officinalis Group (OG)], and the Hybrid Peony Cultivar Group [Hybrid Group (HG)] (Li, 1999; Qin, 2004). Paeonia lactiflora Pall. is the parental species of LG, which primarily includes diploid cultivars $(2 n=2 x=10)$. The parents of OG are mainly Paeonia officinalis L. $(2 n=4 x=20)$, Paeonia tenuifolia L. $(2 n=$ $2 x=10)$, and Paeonia anomala L. $(2 n=2 x=10)$; whereas the parents of HG includes $P$. officinalis $(2 n=4 x=20)$, Paeonia macrophylla (Albov) Lomakin $(2 n=4 x=20)$, and Paeonia coriacea Retz. $(2 n=4 x=20)$, among others (Hong et al., 2010).

As the structure of angiosperm pollen is weakly affected by the environment (Salmaki et al., 2008; Walker, 1974) the structure of

\footnotetext{
Received for publication 28 Dec. 2015. Accepted for publication 1 Mar. 2016. This work was financially supported by the National Natural Science Foundation of China (31400591) and Co-building Program of Beijing Municipal Commission of Education (BLCXY201527).

We thank Prof. David Byrne from Texas A\&M University for providing helpful advice and edits about this paper.

Jaime A. Teixeira da Silva and Xiaonan Yu planned and devised the experiments. Lihong Hao and Hui Ma analyzed the pollen. All authors developed all drafts of the manuscript, approved it for publication, and take public responsibility for its content.

${ }^{1}$ Corresponding author. E-mail: yuxiaonan626@126.com.
}

herbaceous peony pollen is thus likely be more stable, and can reflect common characteristics of a genus or family and define plant origin and evolutionary relationships (Zhang et al., 2014). Wang (2006) indicated, in studies of tree peony (Paeonia decomposita Hand.-Mazz.) and herbaceous peony (Paeonia intermedia C.A. Mey.), that pollen sterility is directly related to its size. In the genus Rosa L., Ma and Chen (1991) confirmed the genetic relationship between hybrid offspring and their parents by comparing pollen exine ornamentation.

To date, many researchers have paid more attention to tree peony than to herbaceous peony. As a result, there is little research on the genetic diversity in section Paeonia (Yu et al., 2012). Xi (1984) observed few differences in the pollen morphology of nine Paeonia species (Paeonia delavayi Franch., Paeonia szechuanica Fang., Paeonia mairei H. Lév., Paeonia anomala, P. lactiflora, Paeonia suffruticosa Andr., Paeonia veitchii Lynch., Paeonia obovata Maxim., and Paeonia sinjiangensis K.Y. Pan.) when examined by light microscopy (LM) and SEM. In palynological studies, exine ornamentation examined by SEM is usually used to identify a species. Guo et al. (2005) found a close relationship between $P$. veitchii, $P$. obovata, $P$. sinjiangensis, and $P$. anomala var. intermedia. Jin et al. (2005) found that each of 15 P. lactiflora cultivars showed distinct pollen morphology when examined with SEM.

Three methods are most frequently used to study pollen morphology: LM, SEM, and transmission electron microscopy (TEM). TEM is often used to observe the ultrastructure to explore the structure and composition of the pollen wall. For 
Table 1. Chromosome number, flower color, blooming date (2013), group, and origin of the 26 herbaceous peony cultivars used in this pollen morphology research.

\begin{tabular}{|c|c|c|c|c|c|c|}
\hline Code & Cultivar & Ploidy $^{z}$ & Flower color & Blooming date & Group & Origin, country \\
\hline$\overline{\mathrm{A}}$ & Scarlett O'Hara & $2 n=2 x=10$ & Red & 31 Apr. & Hybrid & Glasscock Falk, the United States \\
\hline B & Paula Fay & $2 n=2 x=10$ & Pink & 5 May & Hybrid & Fay, the United States \\
\hline $\mathrm{C}$ & Alexander Fleming & $2 n=2 x=10$ & Pink & 2 May & Lactiflora & Blonk, The Netherlands \\
\hline $\mathrm{E}$ & Sarah Bernhardt & $2 n=2 x=10$ & Pink & 9 May & Lactiflora & Lemoine, France \\
\hline $\mathrm{F}$ & Kansas & $2 n=2 x=10$ & Bright red & 11 May & Lactiflora & Bigger, the United States \\
\hline G & Charle's White & $2 n=2 x=10$ & White & 8 May & Lactiflora & Klehm the United States \\
\hline I & Buckeye Belle & $2 n=3 x=15$ & Dark red & 6 May & Hybrid & Walter Mains, the United States \\
\hline $\mathrm{J}$ & Brightness & $2 n=3 x=15$ & Brilliant red & 15 May & Hybrid & Glasscock, the United States \\
\hline K & Red Red Rose & $2 n=3 x=15$ & Red & 27 Apr. & Hybrid & Saunders, the United States \\
\hline $\mathrm{L}$ & Flame & $2 n=3 x=15$ & Coral & 28 Apr. & Hybrid & Glasscock, the United States \\
\hline M & Halcyon & $2 \mathrm{n}=3 x=15$ & Pure white & 11 May & Hybrid & Saunders, the United States \\
\hline $\mathrm{N}$ & Apache & $2 n=3 x=15$ & Red & 20 May & Hybrid & Wolfe-Bigger, the United States \\
\hline $\mathrm{S}$ & Pink Teacup & $2 n=3 x=15$ & Pink & 30 Apr. & Hybrid & Hollingsworth, the United States \\
\hline $\mathrm{T}$ & Coral 'n Gold & $2 n=3 x=15$ & Rose coral & 5 May & Hybrid & Klehm, the United States \\
\hline $\mathrm{U}$ & Laddie & $2 n=3 x=15$ & Bright red & 3 May & Hybrid & Glasscock, the United States \\
\hline $\mathrm{V}$ & John Harvard & $2 n=3 x=15$ & Dark red & 4 May & Hybrid & Auten, the United States \\
\hline $\mathrm{W}$ & Paladin & $2 n=3 x=15$ & Pink & 5 May & Hybrid & Saunders, the United States \\
\hline $\mathrm{X}$ & Pink Hawaiian Coral & $2 n=3 x=15$ & Pink coral & 5 May & Hybrid & Klehm, the United States \\
\hline Y & Athena & $2 n=4 x=20$ & Ivory & 5 May & Hybrid & Saunders, the United States \\
\hline Z & Cream Delight & $2 n=4 x=20$ & Cream & 10 May & Hybrid & Reath, the United States \\
\hline
\end{tabular}

zPublished in Ma (2014).

example, Tellería et al. (2013) and Xu and Ronse de Craene (2013) used TEM to study the ultrastructure of the pollen wall in Compositae and Annonaceae, respectively. A limitation of LM observations is the level of detail in pollen grain surface sculpture that is discernable. The detail that is available from SEM is often required for taxonomic studies (Kodela, 2006). In this study, the pollen morphology, including shape, size, and surface sculpture, of 26 herbaceous peony cultivars with different ploidy levels were examined to provide a useful palynological basis for studying kinship and taxonomy among peonies and to advance hybrid peony breeding.

\section{Materials and Methods}

Plant materials. Fresh pollen grains of the 26 cultivars cultivated at the experimental farm of the Beijing Forestry University were collected from mature stamens in Apr. and May 2013 (Table 1). Most of the cultivars introduced from United States were cultivated in Beijing for more than 3 years. Fresh pollen grains were dried naturally or in silica gel. Dry pollen was used for SEM observations.

Scanning electron microscopy. Pollen grains were directly mounted on stubs and sputtered with gold. The shape and surface ornamentations of pollen grains were examined in detail with an electron microscope (S-3400N; Hitachi, Tokyo, Japan). Photographs of pollen grains were taken at $\times 200$, $\times 2500$, and $\times 10,000$ magnifications.

Methods of Measurement AND ANALYsis. Twenty pollen grains of each cultivar were measured by the software Autocad
2010 (Autodesk, San Rafael, CA). Measurements included P, E, P/E, D, W, and D/W. Experimental data were analyzed with SPSS (version 18.0; IBM, Armonk, NY), and the Duncan's multiple range test $(P<0.05)$ was used for mean separation. In addition, the partial correlation I between these six indexes was analyzed.

The $\mathrm{P} \times \mathrm{E}$ value represents the size of pollen grains, whereas $\mathrm{P} / \mathrm{E}$ represents pollen shape. If $\mathrm{P} / \mathrm{E}>2$, it is perprolate, and if $1.14<\mathrm{P} / \mathrm{E}<2$, it is subprolate (Wang and Wang, 1983). Pollen characteristics were observed in equatorial view as well as in polar view, including pollen shape, the type of perforations and exine ornamentation, which were all based on SEM images. Descriptive palynological terminology follows that used by Erdtman $(1943,1952,1969)$ and Punt et al. (2007). Finally, based on the data of six indices (P, E, P/E, D, W, and D/W), Q cluster analysis within SPSS was used to develop a dendrogram.

\section{Results}

Characteristics of pollen morphology. The pollen of 26 cultivars had different morphological characteristics (Fig. 1). The measurements of pollen characteristics and a description of pollen morphology are shown in Tables 2 and 3, respectively. Of note, 'Paula Fay' (B) had the largest pollen $(\mathrm{P} \times \mathrm{E}=53.70 \times$ $24.78 \mu \mathrm{m})$, whereas 'Apache' $(\mathrm{N})$ had the smallest pollen $(\mathrm{P} \times$ $\mathrm{E}=27.19 \times 17.69 \mu \mathrm{m})$. The range of $\mathrm{P} / \mathrm{E}$ was 1.54 to 2.26 , with 'Athena' (Y) displaying the maximum value (2.26), and 'Apache' $(\mathrm{N})$ the minimum value (1.54). The length of the 

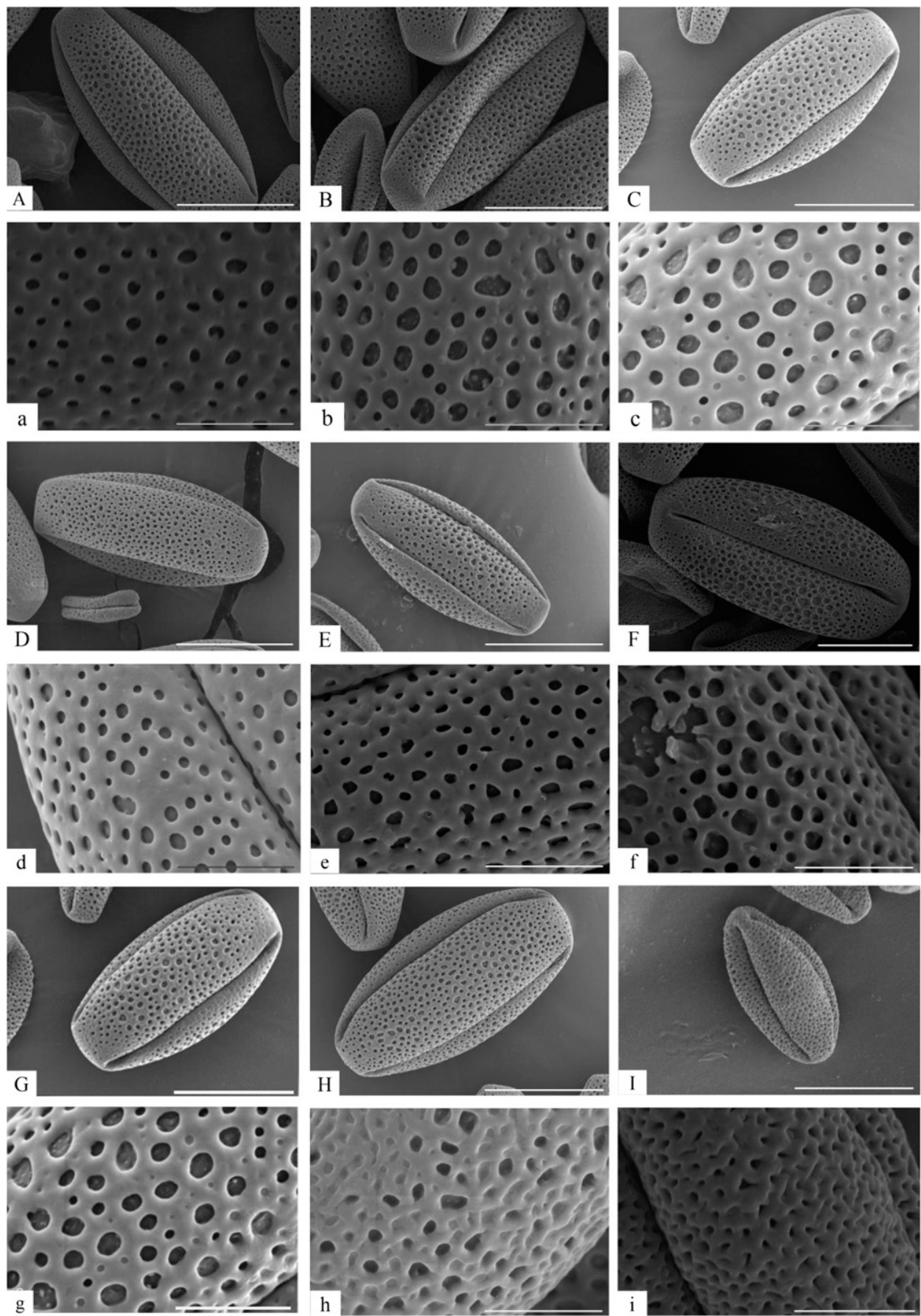

Fig. 1. Observation of pollen morphology on 26 herbaceous peony cultivars. $A-Z=$ the shape of single pollen grain, a-Z $=$ the surface ornamentation. The pollen morphology of diploid, triploid, and tetraploid cultivars is shown in A-H, I-X and Y, and Z, respectively. Scale bars: $20 \mu \mathrm{m}(\mathrm{A}-\mathrm{Z}), 10 \mu \mathrm{m}$ (a), $5 \mu \mathrm{m}$ (b-Z).

polar axis ranged from 27.19 to $53.70 \mu \mathrm{m}$. The length of the equatorial axis ranged from 15.95 to $26.81 \mu \mathrm{m}$. 'Cream Delight' $(Z)$ had the longest equatorial axis, whereas 'Paladin' (W) had the shortest one.

The pollen grains of all 26 peony cultivars were of the tectate-perforate type, but varied in perforation aperture. The reticular type of pollen had sizes ranging from 0.26 to $0.80 \mu \mathrm{m}$. 'Laddie' (U) had the smallest aperture and 'Alexander Fleming' (C) had the largest. D ranged from 0.27 to $1.16 \mu \mathrm{m}$ and $\mathrm{D} / \mathrm{W}$ ranged from 0.49 to 2.18. 'Buckeye Belle' (I) and 'Cream
Delight' $(Z)$ respectively displayed the minimum and maximum values of $\mathrm{D}$ and $\mathrm{D} / \mathrm{W}$. Although the pollen exine sculpture of all cultivars was reticulate, it was divided into three subtypes: smooth-reticulate, rugulate-reticulate, and subcerebroreticulate (Table 3). The exine of most pollen grains from triploid cultivars showed rugulate-reticulate surface ornamentation, except for Nosegay $(\mathrm{O})$ and Roselette $(\mathrm{P})$, which had a smooth-reticulate exine and were similar to the pollen collected from all diploid cultivars and the tetraploid cultivar Cream Delight (Z) (Fig. 1a-X and $\mathrm{z}$ ). The other tetraploid 

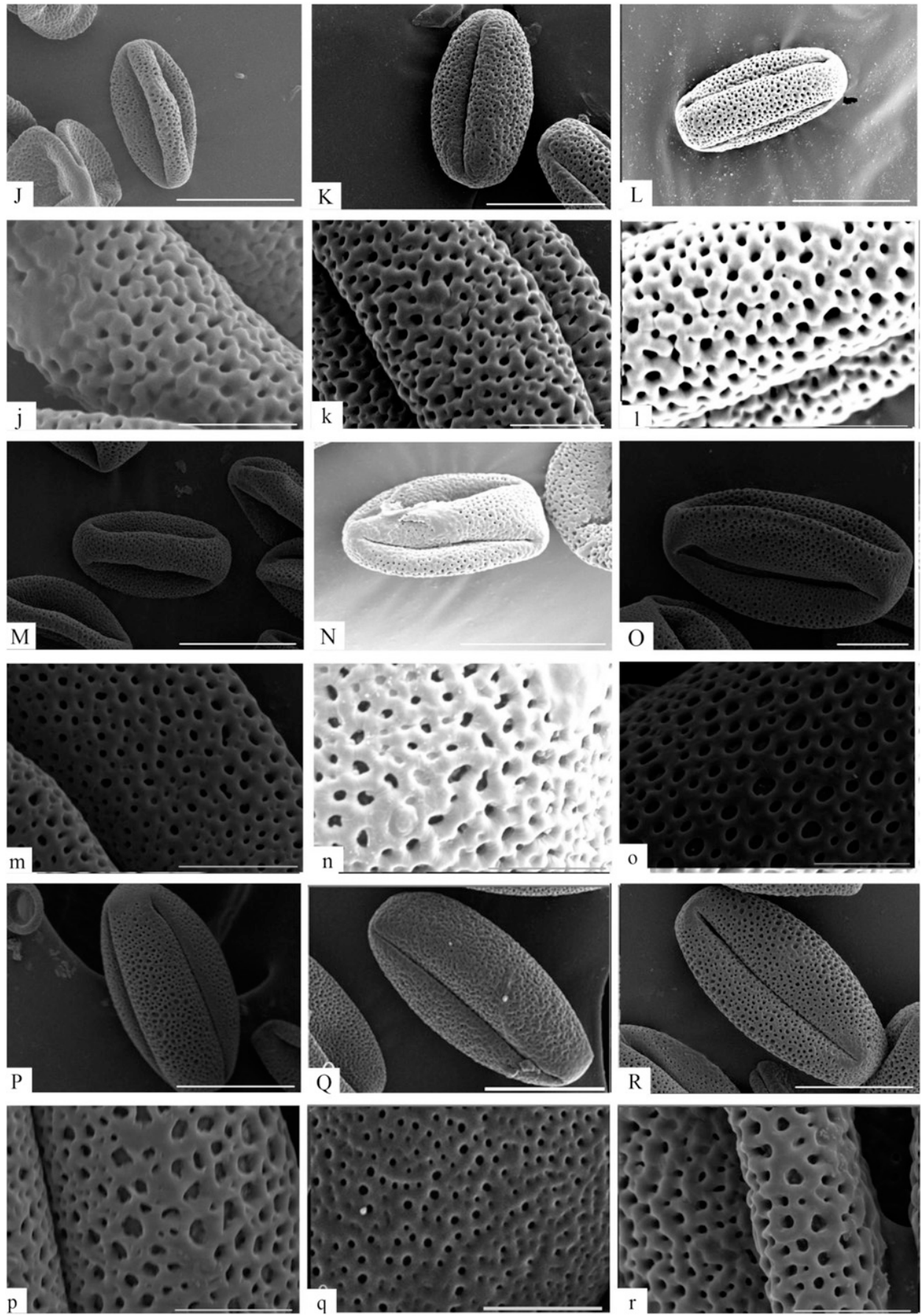

Fig. 1. (Continued)

cultivar Athena (Y) displayed a subcerebro-reticulate type of exine (Fig. 1y).

COMPARISON OF POLLEN SHAPE AND SIZE IN CULTIVARS WITH DIFFERENT CHROMOSOME PLOIDY. The size of pollen grains is related to ploidy in the species of potato [Solanum L. (Bamberg and Hanneman, 1991)] and rose [Rosa L. (Jacob and Pierret, 2000)]. Six pollen indices differed among the 26 peony cultivars assessed in this study (Table 2). The morphological characteristics of diploid $(\mathrm{A}-\mathrm{H})$ and tetraploid $(\mathrm{Y}$ and $\mathrm{Z}$ ) pollen were different from triploid $(\mathrm{I}-\mathrm{X})$ pollen.
The P/E ratio of diploid cultivars ranged from 1.95 to 2.19 . The diploid pollen grains were perprolate except for 'Alexander Fleming' (I), which had subprolate pollen grains (Table 3 ). The pollen grains of diploid cultivars were ellipsoidal in equatorial view and rounded trifid in polar view with tricolporate structures. The poles of pollen grains were mainly flat in cross-sectional view with a few being circular or arc shaped. Moreover, the shape and size of pollen grains were organized, regular, and satiated (Figs. 1A-H, 2A, 2D, 3B, 3D).

The $\mathrm{P} / \mathrm{E}$ ratio of triploid cultivars ranged from 1.54 to 2.20 . Most of the pollen grains were subprolate with empty flat shells, 

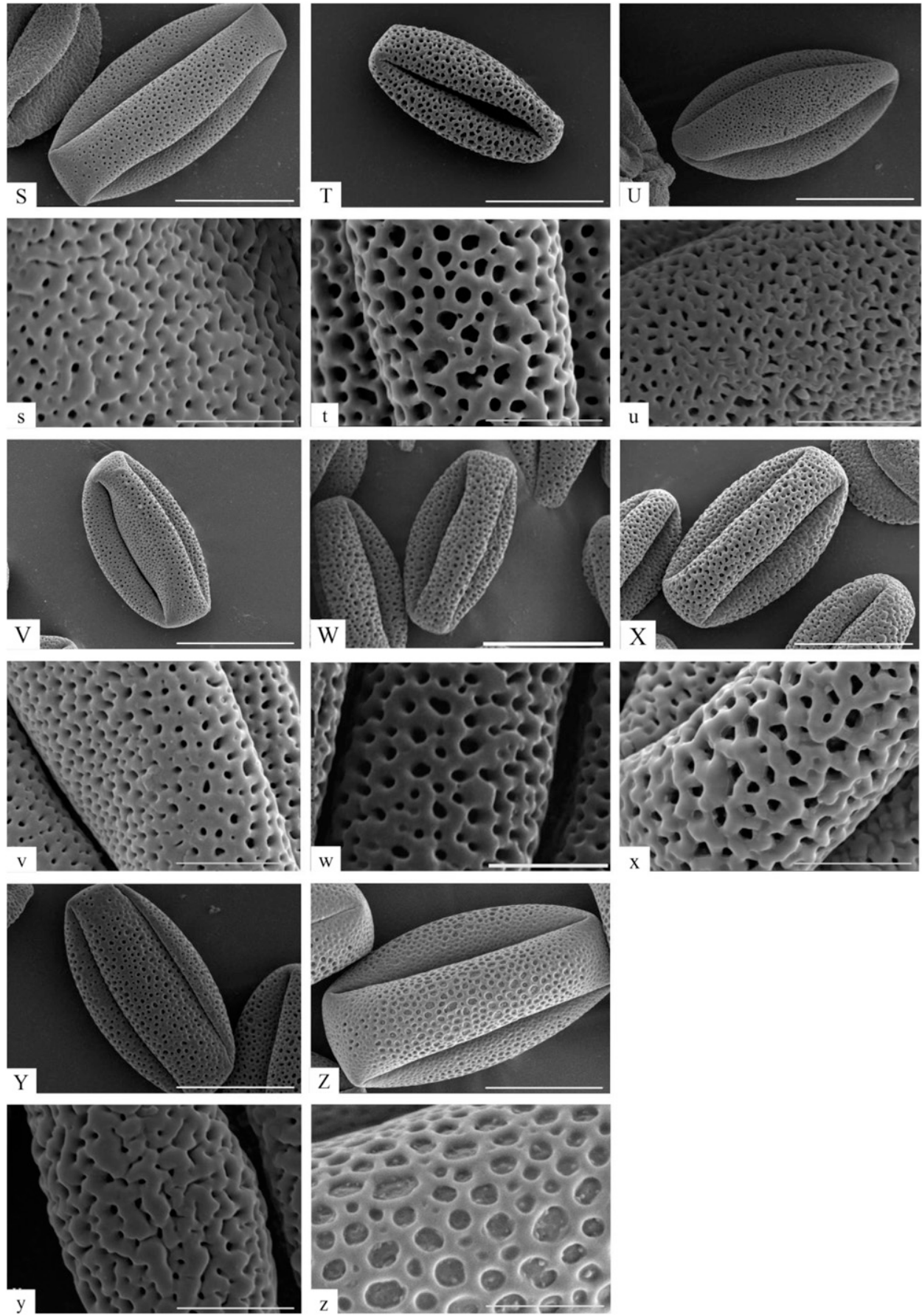

Fig. 1. (Continued)

except for 'Roselette' (P), 'Old Faithful' (Q), 'Pink Teacup' $(\mathrm{S})$, and 'Laddie' (U), which were perprolate. The polar and equatorial axes were difficult to distinguish in some of the heteromorphic pollen. SEM observations showed that the pollen of triploid cultivars was on average smaller but more variable in size than the pollen of the diploid and tetraploid cultivars (Figs. 1I-X, 2N, 3J, 3M). In addition, some pollen grains were damaged while others stuck together.

The $\mathrm{P} / \mathrm{E}$ ratio of tetraploid cultivar Athena $(\mathrm{Y})$ was 2.26 and that of Cream Delight (Z) was 1.79. This indicated that pollen grains of 'Athena' were more slender than those of 'Cream
Delight'. The shapes of full pollen grains of 'Athena' and 'Cream Delight' were perprolate and subprolate, respectively, and were both trifid-round with three germinal apertures in polar view. However, some pollen grains of 'Athena', whose polar view is shown in Fig. 2Y, were heteromorphic or adhered to each other. 'Athena' had more empty and flat-shelled pollen grains than 'Cream Delight'. The pollen size of the cultivar Athena was similar to that of triploid cultivars, whereas the pollen size of Cream Delight was the largest among all cultivars. The pollen grains of triploid cultivars were most irregular within and among cultivars (Figs. 1Y, 1Z, 3Y, 3Z). 
Table 2. The mean and standard deviation $(n=20)$ of six indices related to the pollen morphology characteristics of 26 herbaceous peony cultivars.

\begin{tabular}{|c|c|c|c|c|c|c|c|}
\hline Code & Cultivar & $\begin{array}{c}\mathrm{P}[\text { mean } \pm \mathrm{SD} \\
(\mu \mathrm{m})]\end{array}$ & $\begin{array}{c}\mathrm{E}[\text { mean } \pm \mathrm{SD} \\
(\mu \mathrm{m})]\end{array}$ & $\mathrm{P} / \mathrm{E}($ mean $\pm \mathrm{sD})$ & $\begin{array}{c}\mathrm{D}[\text { mean } \pm \\
\mathrm{SD}(\mu \mathrm{m})]\end{array}$ & $\begin{array}{c}\mathrm{W}[\text { mean } \pm \mathrm{SD} \\
(\mu \mathrm{m})]\end{array}$ & $\mathrm{D} / \mathrm{W}($ mean $\pm \mathrm{SD})$ \\
\hline $\bar{A}$ & Scarlett O'Hara & $51.03 \pm 3.90 \mathrm{ij}^{\mathrm{z}}$ & $23.26 \pm 1.49 \mathrm{gh}$ & $2.19 \pm 0.11$ ef & $0.69 \pm 0.13 \mathrm{gh}$ & $0.61 \pm 0.10 \mathrm{defg}$ & $1.14 \pm 0.05 \mathrm{cdef}$ \\
\hline B & Paula Fay & $3.70 \pm 1.09 \mathrm{kl}$ & $4.78 \pm 1.16 \mathrm{hi}$ & & $47 \pm 0.10 \mathrm{cdef}$ & & \\
\hline $\mathrm{D}$ & Nippon Beauty & $4.17 \pm 3.0$ & $20.41 \pm 1.91 \mathrm{defg}$ & $2.17 \pm$ & $0.44 \pm 0$ & $0.41 \pm 0.0$ & bcde \\
\hline $\mathrm{E}$ & Sarah Bernhardt & $40.41 \pm 0.39 \mathrm{defg}$ & $19.01 \pm 0.72 \mathrm{bcdef}$ & & $.52 \pm 0$ & $0.59 \pm 0$ & \\
\hline F & Kansas & $42.90 \pm 1.75 \mathrm{defg}$ & $19.59 \pm 0.52 \mathrm{ij}$ & $2.19=$ & $0.50 \pm 0$ & $0.59 \pm 0.1$ & bcd \\
\hline $\mathrm{H}$ & White Wings & $4.45 \pm 0$ & $20.53 \pm 1.33 \mathrm{efg}$ & 4 bcde & $0.61 \pm 0$ & $0.72 \pm 0.07 \mathrm{gh}$ & $5 \mathrm{def}$ \\
\hline & & $.64 \pm 0$ & $18.37 \pm 1.2$ & & a & $0.57 \pm 0$ & \\
\hline & Brig & $.68 \pm 1$ & $16.54 \pm 1.7$ & & $48 \pm$ & $0.50 \pm 0$ & bcde \\
\hline K & & $.84 \pm 6$ & $20.40 \pm 0$ & & $\mathrm{~cd}$ & $0.54 \pm 0$ & \\
\hline $\mathrm{L}$ & Flame & $0.64 \pm 4$ & $16.83 \pm 2$. & 1.8 & $0.47 \pm($ & $0.47 \pm 0$ & $\mathrm{~cd}$ \\
\hline M & & $.64 \pm$ & $20.72 \pm 0$ & & cdef & de & cde \\
\hline $\mathrm{R}$ & & $41.49 \pm 4$ & $21.27 \pm 1.6$ & 2 bcdef & $0.61 \pm 0$ & $0.54 \pm 0$ & cdef \\
\hline S & & $47.88 \pm 1$ & $23.43 \pm 1.6$ & & $0.53 \pm($ & $0.51 \pm 0$ & abcd \\
\hline $\mathrm{T}$ & Coral 'n Gold & $30.89 \pm 2.1$ & $16.06 \pm 2.05$ bcde & $1.92 \pm 0.09 \mathrm{a}$ & $0.67 \pm 0$. & $0.54 \pm 0.06$ bcdef & abd \\
\hline $\mathrm{U}$ & & $39.68 \pm 0.68 \mathrm{efg}$ & $18.17 \pm 1.67 \mathrm{bcdef}$ & $2.20 \pm 0.19$ ef & $0.28 \pm 0.07 \mathrm{a}$ & $0.26 \pm 0.05 \mathrm{a}$ & bcdef \\
\hline $\mathrm{V}$ & John Harvard & $30.15 \pm 1.4$ & $16.98 \pm 0.6$ & $1.78 \pm$ & $0.32 \pm 0$ & $0.40 \pm 0.0$ & bcd \\
\hline W & & $31.04 \pm 1.60 \mathrm{bc}$ & $15.95 \pm 1.30 \mathrm{ab}$ & & $0.40 \pm($ & $0.51 \pm 0.04 \mathrm{fgh}$ & \\
\hline $\mathrm{X}$ & Pink Hawaiian Coral & $31.27 \pm 3.89 \mathrm{bc}$ & $15.96 \pm 1.65$ bcdef & $1.96 \pm 0.05 \mathrm{abcd}$ & $0.40 \pm 0$ & $0.51 \pm 0.02 \mathrm{defg}$ & $0.79 \pm 0.15$ bcde \\
\hline Y & Athena & $32.02 \pm 5.44 \mathrm{ab}$ & $18.44 \pm 2.71 \mathrm{ab}$ & $2.26 \pm 0.24 \mathrm{f}$ & $0.42 \pm 0.12 \mathrm{abcd}$ & $0.46 \pm 0.09 \mathrm{bcd}$ & $0.95 \pm 0.38$ bcde \\
\hline Z & Cream Delight & $47.82 \pm 1.55 \mathrm{hi}$ & $26.81 \pm 1.13 \mathrm{ij}$ & $1.79 \pm 0.13 \mathrm{ab}$ & $1.16 \pm 0.03 \mathrm{bc}$ & $0.54 \pm 0.08$ bcdef & $2.18 \pm 0.25 \mathrm{~g}$ \\
\hline
\end{tabular}

${ }^{\mathrm{z} D i f f e r e n t ~ l e t t e r s ~ w i t h i n ~ a ~ c o l u m n ~ i n d i c a t e ~ s i g n i f i c a n t ~ d i f f e r e n c e s ~ a t ~} P \leq 0.05$ via Duncan's multiple range test.

$\mathrm{P}=$ polar axis length; $\mathrm{E}=$ equatorial axis length; $\mathrm{D}=$ perforation diameter; $\mathrm{W}=$ ridge width.

COMPARISON OF POLLEN GERMINAL APERTURE AND SURFACE ORNAMENTATION IN CULTIVARS WITH DIFFERENT CHROMOSOME PLOIDY. The germinal aperture of the full pollen grains of diploid cultivars was tricolporate and was sometimes near the poles. However, the surface ornamentation varied, especially in pollen from cultivars with different ploidy. The $\mathrm{D} / \mathrm{W}$ ratio of diploid cultivars ranged from 0.74 to 1.19 . The reticulation hole was evenly distributed, although the size and shape differed. Some holes displayed rugulate verrucous points while the surface of muri was smooth and continuous (Fig. 1a-h).

The $\mathrm{D} / \mathrm{W}$ ratio of triploid cultivars ranged from 0.49 to 1.46 . Most of the pollen grains were shriveled, the exine was invaginated and the germinal grooves were not obvious. The pollen grains had a rugulate exine sculpture and the muri were prominent. However, the surface ornamentation of 'Nosegay' (O) and 'Old Faithful' (Q) was similar to that of the diploid cultivars (Fig. 1o and q). The meshes of triploid cultivar pollen grains with irregular shapes and various sizes were unevenly distributed. Their surface ornamentation was highly diverse with many abnormal pollen grains (Fig. 1i-x), which may be because with three sets of chromosomes meiosis is disrupted resulting in many unbalanced gametes.

The D/W ratio of tetraploid cultivar Athena (Y) was 0.95 , but that of Cream Delight $(Z)$ was 2.18. Full pollen grains from tetraploid cultivars differed in their surface ornamentation (Fig. 1y and $\mathrm{z}$ ). The surface ornamentation of the cultivar Athena (Y) was similar to that of the triploid cultivars, but it displayed a brain striatum-like patterning, whereas the surface ornamentation of Cream Delight $(Z)$ was similar to that of pollen grains from diploid cultivars, except that the muri were narrower with rugulate verrucous points. In addition, mesh sizes were diverse and shapes were irregular. In particular, the mesh size of 'Cream Delight' $(Z)$ was larger than that of other cultivars.

Cluster analysis. Six pollen indicators were used in $Q$ cluster analysis to analyze the genetic relationship among the 26 peony cultivars. These cultivars could be divided into three groups with a distance of $\mathrm{L}=18.5$ (Fig. 4). The index data of Groups I, II, and III are shown in Table 4.

Group I includes 13 cultivars, nine of which belong to LG except Picotee (I), Halcyon (M), Pink Teacup (S), and Athena (Y), which belong to HG. Eight cultivars were diploid except four HG cultivars and Old Faithful (Q), which are triploid. The pollen morphology of this group was distinguished by a relatively smooth surface and their reticulation holes had a regular shape and homogenous size.

Group II includes 12 triploid cultivars that belong to $\mathrm{HG}$. Among them, 'Nosegay' (O) and 'Roselette' (P) were in the same cluster, whereas 'Laddie' (U) formed a separate group. The other nine cultivars clustered together. Within this group, 'Red Red Rose' (K) and 'Paladin' (W) were clustered together, and 'Buckeye Belle' (I), 'Brightness' (J), 'Flame' (L), and 'Pink Hawaiian Coral' (X) were clustered as a small group. The pollen grains of this latter subgroup had different shapes, the exine sculpture was rough and the reticulate holes were irregular in shape and had various sizes. 
Table 3. Comparison of pollen shape and exine sculpture type among the 26 herbaceous peony cultivars, $\mathrm{n}=20$.

\begin{tabular}{|c|c|c|c|c|c|}
\hline$\overline{\text { Code }}$ & Cultivar & $\mathrm{P} \times \mathrm{E}(\mu \mathrm{m})$ & $\mathrm{P} / \mathrm{E}$ & Pollen shape & Exine sculpture type \\
\hline$\overline{\mathrm{A}}$ & Scarlett O'Hara & $51.03 \times 23.26$ & 2.19 & Perprolate & Smooth-reticulate \\
\hline B & Paula Fay & $53.70 \times 24.78$ & 2.17 & Perprolate & Smooth-reticulate \\
\hline $\mathrm{C}$ & Alexander Fleming & $40.40 \times 20.73$ & 1.95 & Prolate & Smooth-reticulate \\
\hline $\mathrm{D}$ & Nippon Beauty & $44.17 \times 20.41$ & 2.17 & Perprolate & Smooth-reticulate \\
\hline $\mathrm{E}$ & Sarah Bernhardt & $40.41 \times 19.01$ & 2.13 & Perprolate & Smooth-reticulate \\
\hline $\mathrm{F}$ & Kansas & $42.90 \times 19.59$ & 2.19 & Perprolate & Smooth-reticulate \\
\hline G & Charle's White & $42.02 \times 19.95$ & 2.11 & Perprolate & Smooth-reticulate \\
\hline $\mathrm{H}$ & White Wings & $44.45 \times 20.53$ & 2.17 & Perprolate & Smooth-reticulate \\
\hline I & Buckeye Belle & $30.64 \times 17.28$ & 1.78 & Prolate & Rugulate-reticulate \\
\hline $\mathrm{J}$ & Brightness & $30.68 \times 17.29$ & 1.78 & Prolate & Rugulate-reticulate \\
\hline K & Red Red Rose & $32.84 \times 16.54$ & 1.99 & Prolate & Rugulate-reticulate \\
\hline $\mathrm{L}$ & Flame & $30.64 \times 16.83$ & 1.82 & Prolate & Rugulate-reticulate \\
\hline M & Halcyon & $40.64 \times 20.72$ & 1.96 & Prolate & Rugulate-reticulate \\
\hline $\mathrm{N}$ & Apache & $27.19 \times 17.19$ & 1.54 & Prolate & Rugulate-reticulate \\
\hline $\mathrm{O}$ & Nosegay & $35.27 \times 19.71$ & 1.81 & Prolate & Smooth-reticulate \\
\hline $\mathrm{P}$ & Roselette & $35.17 \times 17.74$ & 2.00 & Perprolate & Smooth-reticulate \\
\hline Q & Old Faithful & $34.04 \times 16.28$ & 2.09 & Perprolate & Rugulate-reticulate \\
\hline $\mathrm{R}$ & Picotee & $41.49 \times 21.27$ & 1.95 & Prolate & Rugulate-reticulate \\
\hline S & Pink Teacup & $47.88 \times 23.43$ & 2.04 & Perprolate & Rugulate-reticulate \\
\hline $\mathrm{T}$ & Coral 'n Gold & $30.89 \times 16.06$ & 1.92 & Prolate & Rugulate-reticulate \\
\hline U & Laddie & $39.68 \times 18.17$ & 2.20 & Perprolate & Rugulate-reticulate \\
\hline $\mathrm{V}$ & John Harvard & $30.15 \times 16.98$ & 1.78 & Prolate & Rugulate-reticulate \\
\hline W & Paladin & $31.04 \times 15.95$ & 1.96 & Prolate & Rugulate-reticulate \\
\hline $\mathrm{X}$ & Pink Hawaiian Coral & $31.27 \times 15.95$ & 1.96 & Prolate & Rugulate-reticulate \\
\hline $\mathrm{Y}$ & Athena & $32.02 \times 18.44$ & 2.26 & Perprolate & Subcerebro-reticulate \\
\hline Z & Cream Delight & $47.82 \times 26.81$ & 1.79 & Prolate & Smooth-reticulate \\
\hline
\end{tabular}

$\mathrm{P}=$ polar axis length; $\mathrm{E}=$ equator axis length.
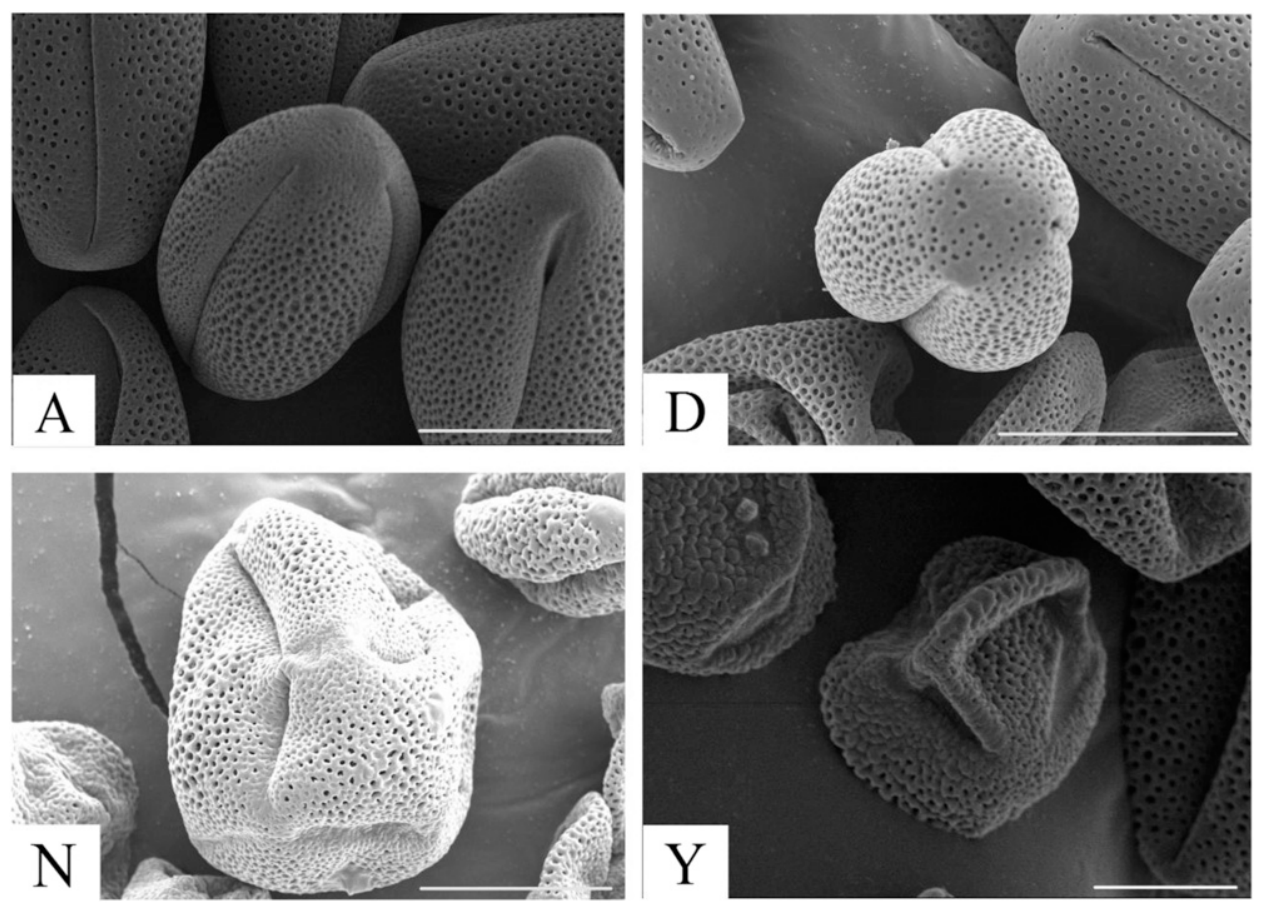

Fig. 2. Scanning electron micrographs of pollen grains of diploid, triploid, and tetraploid herbaceous peony cultivars in polar view: (A) Scarlett O'Hara $(2 n=2 x)$, (D) Nippon Beauty $(2 n=2 x)$, (N) Apache $(2 n=3 x)$, (Y) Athena $(2 n=4 x)$. Scale bars: $20 \mu \mathrm{m}(\mathrm{A}, \mathrm{D}$, and $\mathrm{N}), 10 \mu \mathrm{m}(\mathrm{Y})$.
Group III had only one tetraploid cultivar, Cream Delight $(Z)$. Its pollen grains were largest among the 26 peony cultivars. The muri were homogeneous and smooth, and the meshes were the largest.

EVOLUTIONARY TREND ANALYSIS. The partial correlation ( $r$ value) between $\mathrm{D} / \mathrm{W}$ and $\mathrm{D}, \mathrm{W}, \mathrm{E}$, and $\mathrm{P}$ was $0.750,0.333,0.370$, and 0.251 , respectively. The $\mathrm{P} / \mathrm{E}$ index was not correlated with $\mathrm{D} / \mathrm{W}$ (Table 5). Walker (1974) indicated that the greater the $\mathrm{D} / \mathrm{W}$ ratio, the higher the degree of evolution. If this theory is also applicable to analyzing the evolution of different ploidy levels, as a result of interspecies hybridization, it follows that Group III with the highest $\mathrm{D} / \mathrm{W}(2.18)$ is the most evolved cultivar while the Group I cultivars $(\mathrm{D} / \mathrm{W}=0.93)$ are the most primitive (Table 4). Further studies on how to estimate evolutionary relationships among the filial generation of cultivars of different ploidies are required.

\section{Discussion}

Correlation between pollen SIZE AND STRUCTURE AND PLOIDY LEVEL. Several studies have determined that the size of pollen grains is an effective parameter for the analysis of ploidy level (Lazarevic et al., 2013; Marinho et al., 2014). Consequently, pollen size and shape may serve as a reference index in the identification of ploidy levels, as has been shown by Liu et al. (2003), Yan et al. (2005) and Wang et al. (2015) in watermelon [Citrullus lanatus (Thunb.) Matsum.et Nakai], ramie (Boehmeria nivea L.), and peach (Prunus persica L.), respectively. Yan et al. (2005) indicated that ramie pollen grain size was positively correlated with chromosome ploidy. However, Liu et al. (2003) indicated that pollen grains from triploid watermelon were larger than pollen grains from diploid and tetraploid watermelons. In our study, we found that pollen grains from triploid cultivars were relatively small, and most of them were empty flat shells or had heteromorphic pollen attached. In contrast, the pollen grains from diploid cultivars were full, with a regular and uniform shape, and were larger 

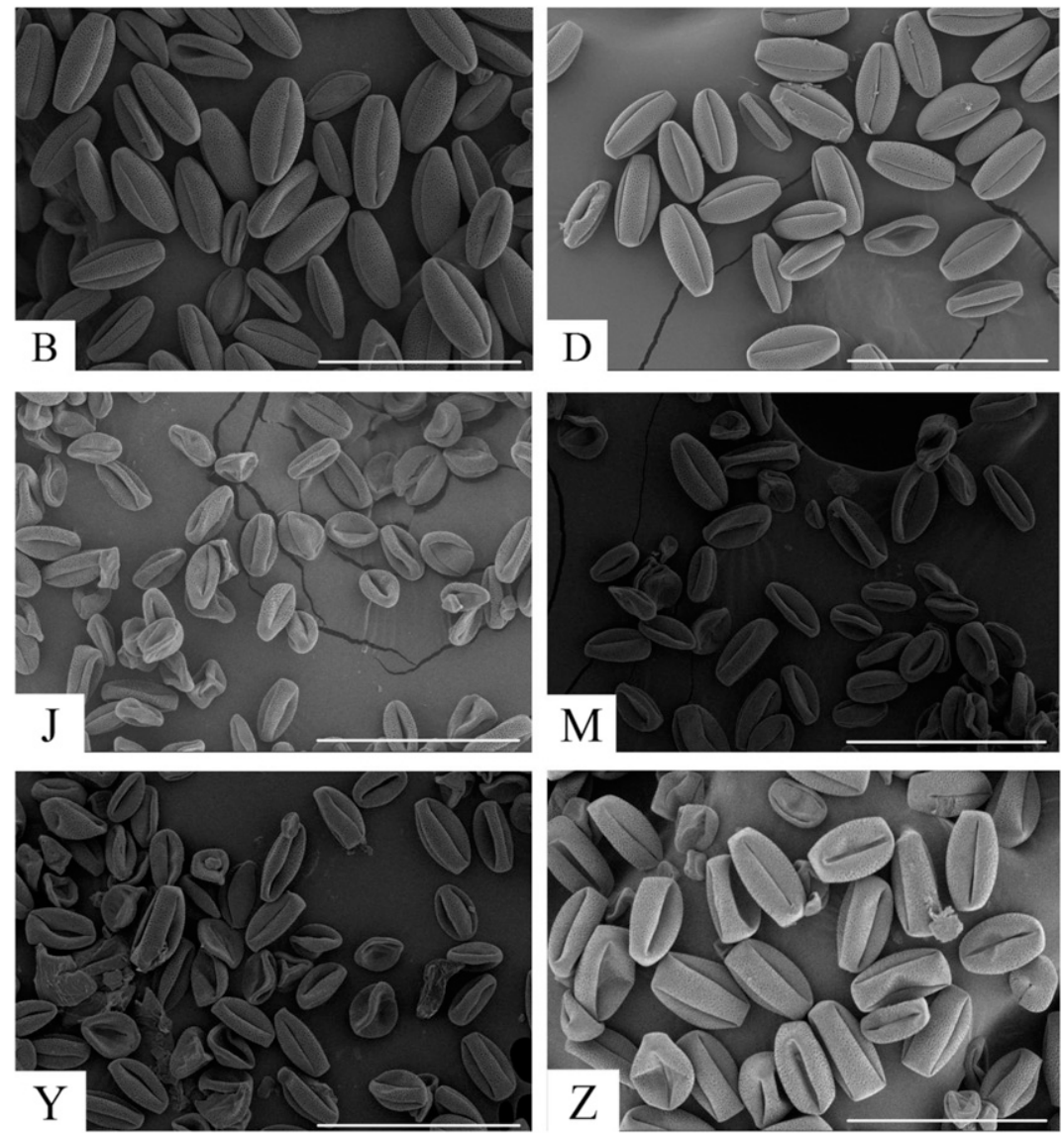

Fig. 3. Comparison of the uniformity of pollen morphology in herbaceous peony cultivars with different ploidies: Paula Fay (B) and Nippon Beauty (D) are diploid cultivars, Brightness (J) and Halcyon (M) are triploid cultivars, Athena (Y) and Cream Delight (Z) are tetraploid cultivars. Scale bars: $100 \mu \mathrm{m}(\mathrm{B}, \mathrm{D}, \mathrm{J}, \mathrm{M}, \mathrm{Y}$, and Z).

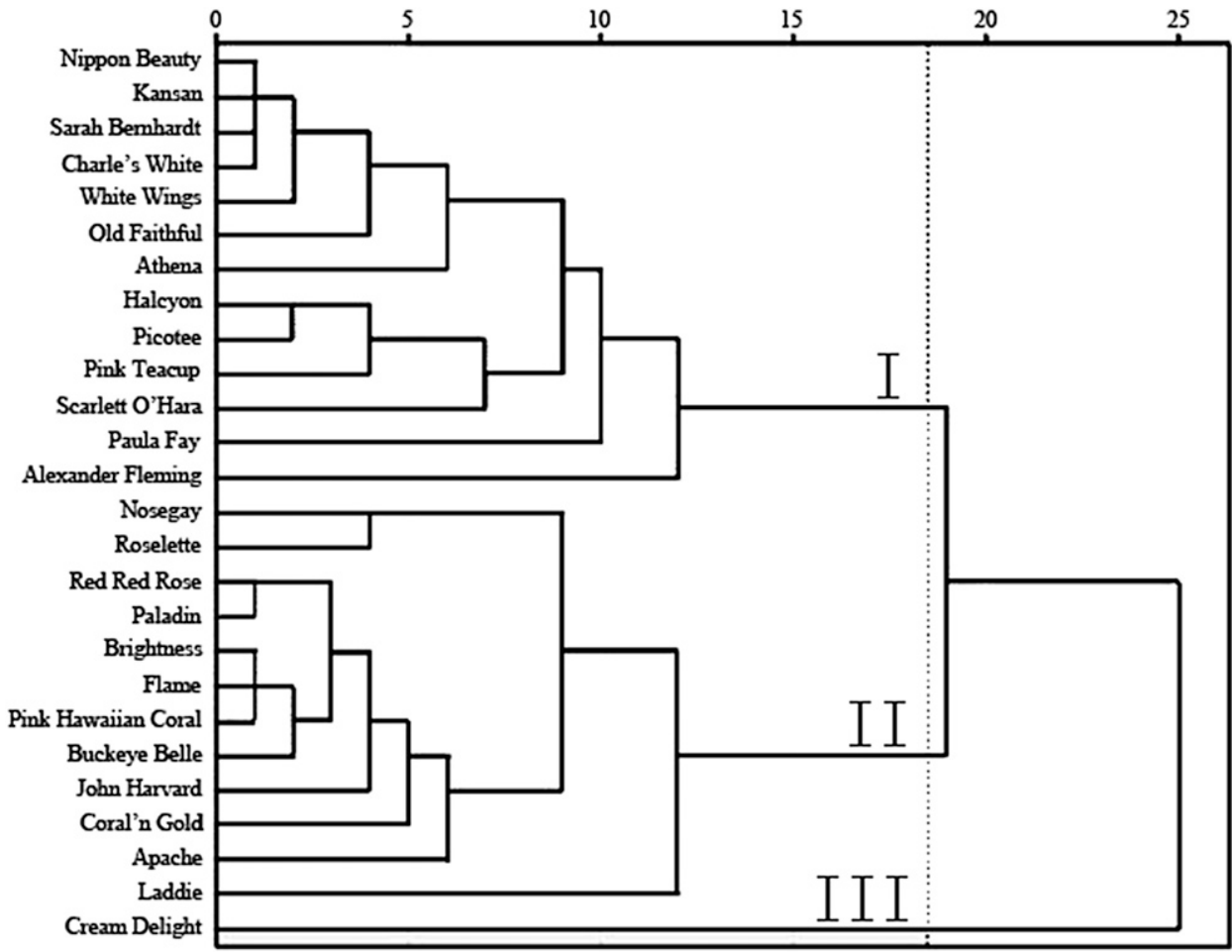

Fig. 4. Clustering results of 26 herbaceous peony cultivars based on pollen characteristics. than the pollen grains from triploid cultivars. Among the 26 cultivars, full pollen grains from cultivar Cream Delight (Z) were largest. Therefore, pollen size and shape may be used as a preliminary method to identify chromosome ploidy in herbaceous peony.

The exine sculpture of all 26 peony cultivars was reticulate based on the Wang (1995) classification. We subdivided this grouping into three types, which were mostly consistent with chromosome ploidy. SEM may serve as an effective and suitable reference method to examine exine sculpture to indicate the ploidy level of herbaceous peony cultivars.

P OLLEN MORPHOLOGY CHARACTERISTICS: APPLICATION TO CULTIVAR IDENTIFICATION AND GENETIC RELATIONSHIP ANALYSIS. Pollen morphological characteristics are stable and of great taxonomic significance. They can reflect common characteristics of a family or genus and can be used for the identification of taxa (Erdtman, 1966; Qureshi et al., 2002; Stix, 1960). Using electron microscopy, especially SEM, to explore pollen ultrastructure is an important method in species or cultivar identification. Arzani et al. (2005), using pollen surface ornamentation combined with tree features to identify 11 apricot (Prunus armeniaca L.) cultivars in Iran, discovered that pollen surface ornamentation of all cultivars, especially ridge and cavity characteristics, were distinct. Guo et al. (2005) observed that some important indicators of pollen morphology in $P$. lactiflora were different from those of three other wild herbaceous peonies, $P$. veitchii, $P$. obovata, and $P$. anomala var. intermedia. They also noted that the classification using classical plant morphological characteristics conformed to the classification based on pollen morphology. Li et al. (2011), using stereo microscopy and SEM, observed the flowers and pollen grains of Pogostemon cablin (Blanco) Benth. (Lamiaceae) from three different habitats, and found that pollen micromorphological features were a good taxonomic indicator to the genus level. Kahraman et al. (2013) and Shabestari 
Table 4. Comparison of the range of six indexes among the three herbaceous peony groups divided by Q cluster analysis.

\begin{tabular}{lccccccc}
\hline Group type & Range of P $(\mu \mathrm{m})$ & Range of E $(\mu \mathrm{m})$ & Range of P/E & Range of D $(\mu \mathrm{m})$ & Range of W $(\mu \mathrm{m})$ & Range of D/W & Avg D/W \\
\hline I & $34.05-51.03$ & $16.28-24.78$ & $1.92-2.19$ & $0.51-0.95$ & $0.52-0.80$ & $0.72-1.18$ \\
II & $27.19-39.68$ & $15.95-19.71$ & $1.53-2.18$ & $0.28-0.69$ & $0.26-0.57$ & $0.78-1.42$ \\
III & 47.82 & 26.81 & 1.79 & 1.16 & 0.54 & 1.02 \\
& & & & & 2.18 & 2.18 \\
\hline
\end{tabular}

$\mathrm{P}=$ polar axis length; $\mathrm{E}=$ equatorial axis length; $\mathrm{D}=$ perforation diameter; $\mathrm{W}=$ ridge width.

Table 5. The partial correlation analysis of six pollen morphological indicators on herbaceous peony cultivars.

\begin{tabular}{|c|c|c|c|c|c|c|c|}
\hline & ntrol variables & $\mathrm{P}$ & $\mathrm{E}$ & $\mathrm{P} / \mathrm{E}$ & $\mathrm{D}$ & W & $\mathrm{D} / \mathrm{W}$ \\
\hline \multirow[t]{3}{*}{$P$} & Correlation & 1.000 & 0.829 & 0.509 & 0.315 & 0.119 & 0.251 \\
\hline & Significance (two tailed) & - & 0.000 & 0.000 & 0.005 & 0.302 & 0.028 \\
\hline & $\mathrm{df}$ & 0 & 0.075 & 75 & 75 & 75 & 75 \\
\hline & Significance (two tailed) & 0.000 & - & 0.661 & 0.000 & 0.406 & 0.001 \\
\hline & $\mathrm{df}$ & 75 & 0 & 75 & 75 & 75 & 75 \\
\hline \multirow[t]{2}{*}{$\mathrm{P} / \mathrm{E}$} & Correlation & 0.509 & 0.051 & 1.000 & 0.070 & 0.065 & 0.064 \\
\hline & df & 75 & 75 & 0 & 75 & 75 & 75 \\
\hline \multirow[t]{3}{*}{$\mathrm{D}$} & Correlation & 0.315 & 0.449 & 0.070 & 1.000 & 0.335 & 0.750 \\
\hline & Significance (two tailed) & 0.005 & 0.000 & 0.546 & - & 0.003 & 0.000 \\
\hline & df & 75 & 75 & 75 & 0 & 75 & 75 \\
\hline \multirow[t]{2}{*}{ W } & Correlation & 0.119 & 0.096 & 0.065 & 0.335 & 1.000 & 0.333 \\
\hline & Significance (two tailed) & 0.302 & 0.406 & 0.572 & 0.003 & - & 0.003 \\
\hline
\end{tabular}

$\mathrm{P}=$ polar axis length; $\mathrm{E}=$ equatorial axis length; $\mathrm{D}=$ perforation diameter; $\mathrm{W}=$ ridge width.

et al. (2013) found pollen characters to be useful to distinguish species within the genus Vicia L. and Centaurea L., respectively.

In our study, observation of the pollen grains of 26 Paeonia cultivars revealed that the pollen grains varied in size, shape, and exine sculpture among the cultivars, especially those with different ploidies. Nevertheless, the cultivars within the same ploidy varied in their muri and mesh sizes, which provided a reference basis for cultivar identification. Understandably, a single method such as SEM or a single technique such as pollen observation is not sufficient to correctly classify these cultivars. A comprehensive analysis would ideally need to combine various other methods and techniques, such as plant phenotype, molecular markers, cytology, and genetics (e.g., Ji et al., 2012).

$\mathrm{Xu}$ et al. (2008) argued that the degree of similarity in pollen grains serves as a preliminary indication of the genetic relationships among cultivars. Wu et al. (2007) used five pollen indices $(\mathrm{P}, \mathrm{E}, \mathrm{P} / \mathrm{E}, \mathrm{D}$, and $\mathrm{W})$ and cluster analysis to discuss evolutionary relationships among lily (Lilium L.) germplasm, showing that species and cultivars could be divided into two sections, Lilium and Sinomartagon. Thus, in the case of wild species of lily, classification of pollen morphology was consistent with the morphological classification.

In our work, we found that most of the cultivars in Group I belonged to LG, which has P. lactiflora as its parent. The tetraploid cultivar Athena (Y) was obtained by Saunders in 1949 (Allan, 1995) through a hybrid combination of $P$. lactiflora $\times[(P$. acrophylla $\times P$. mlokosewitschii $) \times P$. officinalis], so it was clustered with diploid cultivars and not with the tetraploid cultivar. In Group II, 'Nosegay' (O) and 'Roselette' (P), which had $P$. tenuifolia as a common parent, formed a small subgroup. 'Red Red Rose' (K) and 'Paladin' (W), which had $P$. lobata as a common parent, were clustered together. 'Buckeye Belle' (I), 'Brightness' (J), 'Flame' (L), 'Pink Hawaiian Coral' (X), and 'John Harvard' (V), which had $P$. officinalis and $P$. lactiflora as their parents, were clustered into another subgroup. 'Laddie', which had $P$. tenuifolia and $P$. officinalis as its parents, formed a separate subgroup. In Group III, there was only one tetraploid cultivar Cream Delight $(Z)$ whose genetic background is unclear. However, from the results of cluster analysis, it could be inferred that its parents might be distant from $P$. lactiflora and $P$. officinalis. In general, the result of this study is in agreement with the view of Xu et al. (2008) who claimed that pollen characteristics can reflect genetic relationships.

THE APPLICATION OF POLLEN MORPHOLOGICAL CHARACTERISTICS IN CROSS BREEDING. There is a relationship between the pollen morphology of species or cultivars with different ploidies and pollen sterility. Liu et al. (2003) observed and compared pollen morphology of watermelon accessions with different ploidies: the pollen grains of tetraploid plants had different sizes and shapes, and 35\% of all pollen grains were anomalous and many germinal apertures were abnormal. However, they did find that the pollen from diploid plants had uniform size and shape. This result might explain the conclusion reached by Tan et al. (2000) in which pollen germination percentage of diploid watermelon was higher $(93 \%)$ than that of tetraploid (72\%). Ma (2014) obtained similar results, showing that the pollen morphology of diploid herbaceous peony plants was most uniform, and had full pollen grains and high germination $(42 \%$ to $65 \%)$. Most of the pollen grains from triploid 
cultivars were empty and flat, and the percentage germination was low (18\% to $36 \%)$. Moreover, the pollen surface ornamentation of tetraploid cultivar Athena (Y) was close to that of triploid cultivars (germination 35\%) while that of Cream Delight (Z) (germination 41\%) was similar to diploid cultivars (Ma, 2014). These results revealed the relationship between pollen morphological characteristic and germination rate. To our knowledge, cultivars with a high pollen germination rate are usually used as male parents in crossbreeding. Therefore, pollen morphology could be used as a guide for hybridization by assisting with the rational selection of parents.

\section{Literature Cited}

Allan, R. 1995. Peonies. Timber Press, Portland, OR.

Arzani, K., M.A. Nejatian, and G. Karimzadeh. 2005. Apricot (Prunus armeniaca) pollen morphological characterization through scanning electron microscopy using multivariate analysis. N. Z. J. Crop Hort. Sci. 33:381-388.

Bamberg, J.B. and R.E. Hanneman. 1991. Rapid ploidy screening of tuber-bearing Solanum (potato) species through pollen diameter measurement. Amer. Potato J. 68:279-285.

Erdtman, G. 1943. An introduction to pollen analysis. Chronica Botanica, Waltham, MA.

Erdtman, G. 1952. Pollen morphology and plant taxonomy. Angiosperms (An introduction to palynology). Almqvist and Wiksrll, Stockholm, Sweden.

Erdtman, G. 1966. Sporoderm morphology and morphogenesis. A collocation of data and suppositions. Grana Palynol. 6:317-323.

Erdtman, G. 1969. Handbook of palynology-An introduction to the study of pollen grains and spores. Munksgaard, Copenhagen, Denmark.

Guo, X.F., L.Y. Wang, and T. Yuan. 2005. Study on pollen morphology of four wild herbaceous peonies. J. Shandong Agr. Univ. 5:184186 (in Chinese with English abstract).

Hong, D.Y., K.Y. Pan, S.L. Zhou, X.Q. Wang, D.M. Zhang, Y.B. Luo, G.Y. Rao, and L.M. Ma. 2010. Peonies of the world. Royal Botanic Gardens Kew, Richmond, UK.

Jacob, Y. and V. Pierret. 2000. Pollen size and ploidy level in the genus Rosa. Acta Hort. 508:289-292.

Ji, L.J., Q. Wang, J.A. Teixeira da Silva, and X.N. Yu. 2012. The genetic diversity of Paeonia L. Sci. Hort. 143:62-74.

Jin, B., X.D. He, and J.H. Wu. 2005. Pollen morphology and its relationship with cultivar evolution in Paeonia lactiflora. Jiangsu J. Agr. Sci. 21:63-68 (in Chinese with English abstract).

Kahraman, A., O.K. Binzat, and M. Dogan. 2013. Pollen morphology of some taxa of Vicia L. subgenus Vicia (Fabaceae) from Turkey. Plant Syst. Evol. 299:1749-1760.

Kodela, P.G. 2006. Pollen morphology of some rainforest taxa occurring in the Illawarra region of New South Wales, Australia. Telopea 11:346-389.

Lazarevic, M., S. Siljak-Yakovlev, P. Lazarevic, B. Stevanovic, and V. Stevanovic. 2013. Pollen and seed morphology of resurrection plants from the genus Ramonda (Gesneriaceae): Relationship with ploidy level and relevance to their ecology and identification. Turk. J. Bot. 37:872-885.

Li, C.G., Y.G. Wu, and Q.S. Guo. 2011. Floral and pollen morphology of Pogostemon cablin (Lamiaceae) from different habitats and its taxonomic significance. Procedia Eng. 18:295-300.

Li, J.J. 1999. Chinese peony. Beijing: Chinese For. Press, Beijing, China.

Liu, W.G., M. Wang, and Z.H. Yan. 2003. Observation and comparison on pollen morphology of different ploidy watermelon. Acta Hort. Sinica 30:328-330 (in Chinese with English abstract).
Ma, H. 2014. Karyotype analysis and observation of pollen morphology of different ploidy of Paeonia. MSc. Thesis, Beijing For. Univ., Beijing, China. (in Chinese with English abstract).

Ma, Y. and J.Y. Chen. 1991. Pollen morphology of some parent plants and $\mathrm{F}_{1}$ hybrid seedlings for establishing a rejuvenation rose group. $\mathrm{J}$. Beijing Forestry Univ. 18:12-16 (in Chinese with English abstract). Marinho, R.C., C. Mendes-Rodrigues, A.M. Bonetti, and P.E. Oliveira. 2014. Pollen and stomata morphometrics and polyploidy in Eriotheca (Malvaceae-Bombacoideae). Plant Biol. 16:508-511.

Punt, W., P.P. Hoen, S. Blackmore, S. Nilsson, and A. Le Thomas. 2007. Glossary of pollen and spores terminology. Rev. Palaeobot. Palynol. 143:71-81.

Qin, K.J. 2004. The peony (translation). Chinese For. Press, Beijing, China. (in Chinese).

Qureshi, S.J., A.G. Awan, M.A. Khan, and S. Bano. 2002. Palynological study of the genus Tragopogon from Pakistan. Asian J. Plant Sci. 1:283-287.

Salmaki, Y., Z. Jamzad, S. Zarre, and C. Brauchler. 2008. Pollen morphology of Stachys (Lamiaceae) in Iran and its systematic implication. Flora 203:627-639.

Shabestari, E.S.B., F. Attar, H. Riahi, and M. Sheidai. 2013. Pollen morphology of Centaurea L. (Asteraceae) in Iran. Acta Bot. Brasilica 27:669-679.

Stix, E. 1960. Pollen morphologische untersuchungen an compositen. Grana Palynologica 2:41-104.

Tan, S.Y., Z.G. Huang, Y. Liang, W.G. Liu, and X.Q. Huang. 2000. Relationship between germination and growth of pollens of autotetraploid watermelon and endogenous hormones. Acta Agriculturae Boreali Sinica 15:73-79 (in Chinese with English abstract).

Tellería, M.C., G. Sancho, V.A. Funk, I. Ventosa, and N. Roque. 2013. Pollen morphology and its taxonomic significance in the tribe Gochnatieae (Compositae, Gochnatioideae). Plant Syst. Evol. 299:935-948.

Walker, J.W. 1974. Evolution of exine structure in the pollen of primitive angiosperms. Amer. J. Bot. 61:891-902.

Wang, F.X. 1995. Pollen flora of China. Science Press, Beijing, China. Wang, K.F. and X.Z. Wang. 1983. An introduction to palynology. Peking Univ. Press, Beijing, China. (in Chinese).

Wang, S.D., X.C. Wang, J.S. Liu, H.Y. Jiang, and W.J. Wu. 2015. Pollen morphology and germination characteristics of peach triploid germplasms. Northern Hort. 12:80-84 (in Chinese with English abstract).

Wang, S.Q. 2006. Chromosome structural heterozygosity in Paeonia (Paeoniaceae): Evidence from Paeonia decomposita and P. intermedia. PhD Thesis, Inst. Bot., Chinese Acad. Sci.,Beijing, China. (in Chinese with English abstract).

Wu, Z.H., J.S. Shi, M.L. Xi, and G.X. Liu. 2007. Pollen characteristics and relationships of 12 species and 6 cultivars of Lilium. J. Zhejiang For. College 24:406-412 (in Chinese with English abstract).

Xi, Y.Z. 1984. The pollen morphology and exine ultrastructure of Paeonia L in China. Acta Bot. Sin. 26:241-246 (in Chinese with English abstract).

Xu, F.X. and L.P. Ronse de Craene. 2013. Pollen morphology and ultrastructure of selected species from Annonaceae. Plant Syst. Evol. 299:11-24.

Xu, Y.F., K. Zhang, W.Y. Wang, B. Qu, and J.X. Wang. 2008. Pollen morphology of 9 species of genus Iris with scanning electron microscope. J. Shenyang Agr. Univ. 39:733-736 (in Chinese with English abstract).

Yan, C.G., R.F. Cao, Z.D. Li, S.X. Zheng, and G.X. Cui. 2005. Study on the relativity of morphology and ploidy of ramie pollen grains. Hubei Agr. Sci. 3:47-49 (in Chinese with English abstract).

$\mathrm{Yu}$, X.N., L.J. Ji, and Q. Wang. 2012. Research advances in molecular genetic diversity of Paeonia L. J. Beijing Forestry Univ. 4:130-136. (in Chinese with English abstract).

Zhang, X.H., J.A. Teixeira da Silva, J. Duan, and N.H. Xia. 2014. Pollen morphology of Magnolioideae in China and its taxonomic implications. Sci. Hort. 176:170-179. 